\title{
CAMPATH-1 Antigen
}

National Cancer Institute

\section{Source}

National Cancer Institute. CAMPATH-1 Antigen. NCI Thesaurus. Code C38908.

CAMPATH-1 antigen (61 aa, $7 \mathrm{kDa}$ ) is encoded by the human CD52 gene. This protein may play a role in spermatogenesis and lymphocyte biology. 